\title{
National acromegaly registries
}

\section{Luigi Maione $^{1,2,3}$, Philippe Chanson ${ }^{1,2,3}$}

${ }^{1}$ Assistance Publique-Hôpitaux de Paris (AP-HP), Service d'Endocrinologie et des Maladies de la Reproduction, Centre de Référence des Maladies Rares de l'Hypophyse, Hôpital de Bicêtre, F-94276 Le Kremlin-Bicêtre, France;;

${ }^{2}$ UMR-S1185 Université Paris-Sud, Univ Paris-Saclay, F-94276 Le Kremlin-Bicêtre, France;

${ }^{3}$ Institut National de la Santé et de la Recherche Médicale (Inserm) U1185, F-94276 Le Kremlin Bicêtre, France

\section{Correspondence}

Philippe Chanson

Service d'Endocrinologie et des Maladies de la Reproduction

Hôpital Bicêtre

78 rue du Général Leclerc

94275 Le Kremlin Bicêtre

Paris, France

Email: philippe.chanson@bct.aphp.fr 


\begin{abstract}
Acromegaly is a rare disease, associated with multiple organs and systems damage. Thanks to implementation of registries, systematic data gathering, knowledge sharing and standardizing medical practices for optimal care have been greatly improved. Data concerning 19 national acromegaly registries are available, involving more than 16,000 patients. The weighted mean age of diagnosis is 45.2 years and seems stable over time. A macroadenoma is found in $75 \%$ of the cases. The proportion of patients operated (> 80\%) did not change along time. By contrast, use of radiotherapy has decreased while use of medical therapy increased. If judged on IGF-I levels, acromegaly is controlled in $61.3 \%$ of the patients. The disease control rate has improved over time. This is likely due to the development of medical treatment strategies. The collection of data about comorbidities in national registries is much less comprehensive than those about epidemiology, disease control or treatment strategies. The most reported comorbidities are arterial hypertension and diabetes. Data concerning mortality trends are controversial. It seems that cancer has become a leading cause of death in acromegaly patients in the last decade, period in which life expectancy improved, while cardiovascular mortality decreased. In conclusion, acromegaly registries offer a global view of the disease with no " $a$ priori" assumptions. This is of outmost importance, because of the large amount of data and the huge number of associated comorbidities. This will help to establish guidelines for management of this rare disease.
\end{abstract}

Keywords: registry, acromegaly, mortality, epidemiology 
Acromegaly is a rare disease, in most cases related to the hypersecretion of growth hormone (GH) by a pituitary adenoma. Excessive exposure to GH and circulating insulin-like growth factor (IGF)-1 has been associated with multiple organs and systems damage. In the absence of treatment, this condition is also associated with an increase in global morbidity and mortality $[1,2]$. A multimodal therapeutic strategy currently allows the disease control in most cases [3-5].

The diversity of the clinical, biological and therapeutic aspects of a rare disease justifies systematic data gathering, knowledge sharing and, if possible, standardizing medical practices for optimal care. The implementation of registries for rare diseases satisfies, in part, these objectives. This has been the case for acromegaly since many years.

The global and comparative data analysis from different national registries allows to understand the similarities and differences across countries.

\section{The importance of National Disease Registries}

National disease registries provide important and useful information that allow physicians and the scientific community to better understand the epidemiology, the characteristics and the evolution of some diseases. Initially conceived as organized systems using observational study methods to collect uniform data about particular diseases, they finally served not only as systems for data collection and analysis, but also and more importantly, as major institutional catalysts to improve health outcomes over time. Disease registries have undoubtedly helped improving health strategies and reducing the costs of health care, as in the case of hip or cataract surgical procedures [6] Through the use of such registries, health-care providers can compare, identify, and adopt best practices for patients. Moreover, the creation of a national registry for a certain disease is also useful to know and follow-up various epidemiological characteristics, natural history, the efficacy of the disease management, the disease activity 
control, and the rate of disease complications. The information provided by a registry can guide medical strategies and practices of centers that have low patient enrolment.

In order to warrant institutional access to data for health policies, the Institutions / Academic Societies managing data about these diseases should confidentially transmit information to national or supranational organisms. It is of interest that, within the EU, the declaration of national acromegaly registries within the European Rare Disease Network (Orphanet Report series, http://www.orphadata.org) has been provided for only five countries (Austria, Germany, France, Spain and UK).

\section{Main characteristics and geographical distribution of national acromegaly registries}

Nineteen national acromegaly registries have been published in the scientific literature [7-26]. They provide information on both the epidemiology and the disease characteristics, for each country. In addition, the majority of registries reflect the availability of drugs or therapeutic strategies and provide information about different cultures and medical practices.

The major epidemiological characteristics of acromegaly across different countries are summarized in Table 1.

More than 16,000 patients were included in the published registries. If we assume a disease prevalence ranging from 20 to 80 cases per million $[9,21,27,28]$, we can speculate that the territorial studies encompass a population of more than 375 million individuals.

Even if geographical characteristics represent a broad sample of the world population, it should be noted that the distribution of the studied populations is very heterogeneous. It is to be noted that, among the 19 registries, most $(n=13)$ were created and managed in European countries (Figure 1 and Figure 2). Among the six remaining registries, three gathered data from acromegalic populations in North America, one from Iran, one from South Korea and 
one from New Zealand. Populations in Asia and Oceania are therefore under-represented. African and South American populations are not represented.

All the published registries include retrospective data. Mexican [22] and French [25] registries mostly rely on retrospective data, but part of the data is prospectively gathered. The Danish registry collected data on acromegalic patients and compared them to a non-acromegaly control cohort from the general population, by means of the country's National Health Registries [21].

\section{Demographic characteristics of acromegaly in registries}

The main epidemiological characteristics are systematically provided in the registries. They are quite constant across series and have not appeared to change during the last 30 years (Table 1). To underline the importance of the populations' size, the weighted means for all available parameters were calculated.

According to the analysis of different national registries, the demographic characteristics of acromegaly populations are quite homogeneous. The overall weighted mean age of diagnosis is 45.2 years and this is similar in all the reported series (median age ranges between 41 to 50 years according to registries). The condition affects slightly more frequently females (mean ratio $\mathrm{F} / \mathrm{M}=1.24)$. Moreover, the age at diagnosis is significantly higher in women than in men in all the reported studies (by 0 to 7 years).

Two European series reported an unexpected stability in the ages at diagnosis with respect to the year of inclusion from the 1970s to the 2010s in the Danish registry [21] and in the French one [25]. The German registry even showed an increase in the age at diagnosis during the last decades [29]. This could reflect either an absence of improvement in the diagnosis 
performance or a change in the natural history of the disease with a progressive delay in the occurrence of somatotropic adenomas. Assessing the delay between the onset of the first clinical signs and the diagnosis could answer this question. Unfortunately, this parameter is quite imperfect and difficult to analyze. In addition, it is not provided in all the series. This parameter appears to range between 5 to 14 years but does not seem to change throughout the years of publication of the registries.

The tumoral characteristics of somatotropic adenomas upon diagnosis are similar across countries. In $75 \%$ of the cases, the origin of acromegaly consists of a somatotropic pituitary macro-adenoma (range 67-84). This percentage remains stable in relation to the year of publication of the registries. A study identified that the proportion of macroadenomas remained stable throughout the decades. In concordance with the stability of the age at diagnosis, this could suggest that the diagnosis did not occur earlier during the last decades $[25]$.

\section{Management of acromegaly}

\section{Pituitary surgery}

The majority of somatropic adenomas were subjected to pituitary surgery. This information is mentioned in all the reported studies. The weighted mean percentage of operated cases is $80.4 \%$, which corresponds to almost 13,000 procedures and is relatively stable across different countries (ranging from 67 to $90 \%$ ). After examining the rate of surgery over time, it did not appear to change significantly throughout the years. Moreover, no variation in the rates of patients undergoing surgery in relation to the year of publication of the registries is observed.

\section{Radiotherapy}


Unlike surgery, the use of radiotherapy (conventional or stereotactic) varies from country to country. The weighted mean percentage of patients undergoing radiotherapy was $28.8 \%$, but ranged from $9 \%$ to $87 \%$ according to the different countries. All the studies that provide information about the changes in the use of radiotherapy showed a progressive reduction in radiotherapy use in recent years or decades $(6,9,18)$. A progressive decrease in the rate of patients undergoing radiotherapy is also observed in relation to the year of publication (Table 1).

\section{Medical treatment}

On average, $60 \%$ of patients received a medical treatment of any kind to control their acromegaly, which corresponds to more than 9,000 patients medically treated in national registries. The use of medical treatment was variable across the different countries (ranging from 0 to $78 \%$ of the patients). All the available studies addressing the evolution of practices describe an increase in the use of medical treatment with time.

A first-line medical treatment (before or after surgery) was given to $24 \%$ of the patients (weighted average), but this number varied according to the different practices. Indeed, according to ten studies reporting this information, the use of first-line medical treatment for acromegaly was between 0 to $50 \%$. This practice appears to vary more in relation to the country than in relation to the year of publication or patient inclusion period.

When it comes to the medication classes used, most patients were treated with somatostatin analogs (octreotide or lanreotide); followed first by dopamine agonists (bromocriptine, quinagolide, and cabergoline) and later by the $\mathrm{GH}$ receptor antagonist pegvisomant, which was available for the treatment of acromegaly in Europe around the year 2003. The proportion of patients treated by pegvisomant, in parallel to its market availability, has progressively increased throughout the recent years at the expense of other medication classes. 


\section{Evolution of therapeutic choices}

Among the therapeutic approaches, pituitary surgery was preferred in all the series. The surgery success rate alone did not change throughout time, indicating a stability of neurosurgical performance, despite the introduction of new techniques (endoscopy) [30, 31]. This is also related to the persistence of a strong prevalence of macroadenomas at diagnosis, which is a major predicting factor of the surgical outcome. However, the use of radiotherapy strongly decreased with time, everywhere, as illustrated in the French registry (Figure 3). The New Zealand series had the highest proportion of patients undergoing radiotherapy: this cohort included around 200 patients followed between 1964 and 2000, the time before the introduction of somatostatin analogues in this country [7]. The decrease in the use of radiotherapy, irrespective of the type, appears to be a constant reflection of the increased availability/use of medical treatments for acromegaly. As well as the introduction of the GH receptor antagonist pegvisomant, the strategy of combining multiple drugs together appeared to be a contributing factor to the control of more than three-quarters of the patients at the last visit. The data of German and French registries, for example, show a strong similarity in the deployment of their medical strategy $[18,25]$.

\section{Biological disease control}

The definition of disease control differs across registries, by year of publication and the guidelines in place. If the control of acromegaly is judged according to the concentration of circulating IGF-1 (normative data being adjusted for sex and age), the objective is reached for the majority of the patients at the last visit (weighted mean percentage, $61.3 \%$, ranging from 37 to $76 \%$ ). Studies mentioning the disease control rate over time almost always found a significant increase in the rate of patients with controlled disease. This is illustrated in Figure 4 regarding the French Registry, where the proportion of patients with uncontrolled 
acromegaly fell from $54 \%$ before 2001 to about $25 \%$ after 2010 , whereas the proportion of patients with medically controlled disease rose from $18 \%$ to $42 \%$, the proportion of patients with inactive (cured) disease remaining relatively stable, at between $25 \%$ and $35 \%$ [25]. This was also demonstrated in other registries $[12,16,18,32]$. According to the different series, the rate of patients with disease control does not seem to depend on the rate and/or effectiveness of surgical procedures. By contrast, the disease control improvement may well depend on the development of medical treatment strategies. For example, the Iranian series, holding the least proportion of controlled patients (37\%), also has the lowest proportion of medical treatment (27\%), whereas $100 \%$ of their patients underwent surgery [24].

\section{Comorbidities}

The collection of data about comorbidities in national registries is much less comprehensive than those about epidemiology, disease control or treatment strategies (Table 2). The most reported comorbidities are arterial hypertension and diabetes. Weighted mean prevalence of hypertension is $35.7 \%$, varying across registries and ranging from 11 to 54\%. Conversely, type 2 diabetes mellitus is more constant, with a weighted mean prevalence of $27 \%$ (range between 12 and 40\%, according to registries).

Information about other comorbidities is less frequently reported. In Table 2 weighted means for each comorbidity are reported. The prevalence of cancer, carpal tunnel syndrome, cerebrovascular disease and respiratory failure appears to be quite similar across registries. On the contrary, the prevalence of arthritis, sleep apnea syndrome, colorectal polyps and pituitary insufficiency is highly variable, clearly depending on the means of data collection and national habits. 
Although biological indicators (mean $\mathrm{GH}$ concentrations, treatment withdrawal due to hyperglycemia, age and sex-adjusted concentrations of IGF-1) are well documented in national registries, clinical indicators are less frequently reported. In addition, the prevalence of comorbidities is variable from a series to another. This is either due to the comorbidities not being reported or due to the changing means of diagnosis between registries. For example, in some studies, the diagnosis of sleep apnea depends on clinical and anamnestic elements while in others it depends solely on polysomnographic recordings (which are often difficult to obtain rapidly). This is also the case for colonic polyps that are only detected by performing an endoscopic examination. This may be the reason why most polyps and cancers are detected at the time of the diagnosis of acromegaly. On the other hand, hypertension or diabetes are seemingly easier to detect, with more robust and common diagnostic criteria.

Some data obtained from registries may be at variance with data issued from comorbidity targeted studies or studies conducted in expert centers. For example, the strong correlation between GH and/or IGF-1 concentrations and the occurrence of comorbidities observed in many targeted studies [2] is rarely found in registries. Similarly the targeted studies generally conclude that the biological control of the disease have a beneficial effect on comorbidities, while registries data are generally unable to reach such conclusion. In fact, most of targeted studies may contain inclusion biases and, because of their nature and their design, lack of long-term evaluation. Indeed, few targeted studies evaluated, in large longitudinal series, the long-term progression of comorbidities. Moreover, targeted studies are generally monocentric and certainly more subject to confounding. By contrast, data from registries are, in most cases, not particularly focused on a certain aspect of the disease but collect global data without a priori assumptions. If information on comorbidities is sufficient, data from registries could be able to validate those from targeted studies.

\section{Mortality}


Around 850 deaths of acromegaly patients were reported in the nationwide acromegaly registries (over a total of 8,500 patients, Table 3). This information was lacking from some national series (Greece, Malta, Germany, United States, and South Korea). Other registries did not compare mortality with the reference population and hence did not establish a standardized mortality ratio, SMR (Spain, Canada, Austria, Iran). Only the Danish and Finnish cohorts determined, in addition to standardized mortality ratio (SMR), the mortality relative to a control population.

Despite the high number of deaths in the sum of all the studied populations, the number of deaths by series is quite low, and the sample size is often insufficient to draw useful conclusions on the epidemiological level. In addition, for many patients, the cause of death is lacking (provided only in 10 to $50 \%$ of the cases, according to registries). Nevertheless, the predominant causes of death remain cardiovascular diseases and cancers

A recent Finnish publication [33], focusing on mortality in acromegaly patients found a longterm excess risk, particularly involving females. Among 113 deaths, 34\% were related to cardiovascular causes (versus $33 \%$ in the reference population $\mathrm{p}=\mathrm{ns}$ ), and $27 \%$ were related to cancers (versus $27 \%$ in the reference population, $\mathrm{p}=\mathrm{ns}$ ) [33]. The authors suggested that, compared to their older series [9], cardiovascular causes tend to decrease while malignant causes increase, confirming the hypotheses already raised by the Mexican series [22, 32]. Another recent Swedish paper found an excess mortality in acromegaly [26], mainly related to circulatory and malignant diseases. Importantly, they found that mortality significantly declined over time, presumably because of optimization of pituitary surgery, decreased hypopituitarism, reduction of radiotherapy and the availability of new medical treatment options [26]. 
While analyzing mortality data from national registries, one should consider that the relatively high number of patients lost to follow-up is a likely cause of underestimating death rates.

Bolfi et al. recently performed a metanalysis of 26 studies providing the SMR, and evaluated the effect of publication year [34]. They found that from the 17 studies published before 2008, the mortality in acromegaly was increased, while from the nine studies published after 2008, the mortality was not different from the general population (SMR: 1.35, CI: 0.99-1.85). Biochemical control and the availability of medical treatment could have had an impact in this reduction in mortality rate. They also concluded that cancer has become a leading cause of deaths in acromegaly patients in the last decade, period in which life expectancy improved [34].

The reduction in cardiovascular with respect to cancer mortality in acromegaly might be, in fact, a reflection of trends also observed in the general population. It is pertinent to ask if the improvement or even the normalization of the biological disease control is the reason why the acromegaly population is now aligning with the reference population, in epidemiological terms?

\section{The limitations of the registries}

Despite the unquestionable advantages of the registries and the data derived from them, some limitations deserve to be highlighted. First, data entry can vary greatly in quantitative terms from one center to another. The completeness and consequent data homogeneity could be distorted. For certain items, like mortality or loss to follow-up, the absence of information can have important statistical consequences. The other limitation concerns the quality of the coding. Indeed, Dal's study on the Danish population alerts us to the fact that in the national public health databases (in this case, in Denmark), where all the population is registered via International Classification of Diseases ICDs, the predictive positive value for acromegaly 
diagnosis, for example, reaches only 53\% (confidence interval ranging from 46.3 to 59.8) [35]. If multiple hospital admissions receive the same code, the predictive value increases to $75 \%$.

Other limitations of the registries that should be taken into account concern technical aspects. Most registries were developed with "non-dynamic" computer tools that, instead, analyze predefined fields. During follow-up, certain items considered as add-on can have a major importance or new therapeutic developments can appear (for example the use of new drugs, genetic and molecular data, new diagnostic tools, etc).

Data entry can vary quantitatively according to centers. Changes in the definition of comorbidities and diagnostic criteria also represent sources of differences that are difficult to modify retrospectively. On the one hand, the complexity and multiplicity of data can lead to an increase in missing data and/or affect data quality; on the other hand, a registry with too little items could lack useful data for comprehensive analyses and for statistical adjustments.

Other economic aspects influencing data quality should be taken into account: support and assistance, storage of sensitive data in secured servers by computer managers, data entry by local operators, data control, personnel training and operating time dedicated to these tasks.

Despite all those limitations, registries offer a global view of a certain disease with no " $a$ priori" assumptions. When dealing with acromegaly, this is of outmost importance, because of the large amount of data and the huge number of associated comorbidities. For this reason, they complement the more targeted monocentric studies, because they lack methodological bias and mainly look at the long-term evolution of all the aspects of the disease. The introduction of more dynamic tools adapting to the ever-changing landscape of the disease is needed to improve the structure and the subsequent interpretation of registries data. The direct interaction with National Health Services with appropriate compatible platforms might also be 
useful to directly transfer and compare data to the pertinent general population and to avoid unnecessary, and time-consuming data transcriptions. The dissemination of knowledge and data sharing of registries data may permit the establishment of recommendations and guidelines from scientists and experts, homogenize clinical practices and ultimately lower health care costs and improve patient outcomes. 


\section{Practice Points}

- Implementation of registries for rare diseases is of paramount importance for improving knowledge, sharing experience and proposing guidelines for management.

- Age at diagnosis did not change over time, underlining that the very long delay for diagnosis remains similar. With regard to the relation between severity of comorbidity and disease duration, an earlier diagnosis is highly desirable.

- Even if acromegaly control rate has improved during the last decades, almost $40 \%$ of the patients remain uncontrolled, which must lead to intensification of therapy.

- Mortality has likely improved in patients with acromegaly during the last years. Importantly, cancer (and not cardiovascular diseases) seems to be nowadays the primary cause of death in acromegaly.

\section{Research agenda}

- Registries need to be implemented in more and more countries and must include the maximum of patients.

- Global analysis of the data extracted from each registry is of major importance for understanding country-specific management and comparing efficacy of therapeutic strategies for this rare disease.

- The introduction of more dynamic tools adapting to the ever-changing landscape of the disease is needed to improve the structure and the subsequent interpretation of registries data.

- The direct interaction with National Health Services with appropriate compatible platforms is crucial to directly transfer and compare data to the pertinent general population and to avoid unnecessary, and time-consuming data transcriptions. 


\section{Legends of figures}

Figure 1. Geographical distribution of national geographic registries in Europe

Figure 2. Geographical distribution of national geographic registries in the rest of the world.

Figure 3. Evolution of treatment strategies in the French acromegaly registry. Data are the percentages of patients. (A) Distribution of treatment approaches in different follow-up periods. MT, medical treatment; RT, radiotherapy. Adapted from ref [25] with permission.

Figure 4. Evolution of disease status across 4-year follow-up periods in the French acromegaly registry. Histograms indicate the percentages of patients (S.D.). Adapted from ref [25] with permission. 


\section{References}

[1] Chanson P, Salenave S, Kamenicky P. Acromegaly. Handb Clin Neurol. 2014;124:197219.

[2] Colao A, Ferone D, Marzullo P, Lombardi G. Systemic complications of acromegaly: epidemiology, pathogenesis, and management. Endocr Rev. 2004;25:102-52.

[3] Katznelson L, Laws ER, Jr., Melmed S, Molitch ME, Murad MH, Utz A, et al. Acromegaly: an endocrine society clinical practice guideline. J Clin Endocrinol Metab. 2014;99:3933-51.

[4] Melmed S, Bronstein MD, Chanson P, Klibanski A, Casanueva FF, Wass JAH, et al. A Consensus Statement on acromegaly therapeutic outcomes. Nat Rev Endocrinol. 2018;14:552-61.

[5] Giustina A, Chanson P, Kleinberg D, Bronstein MD, Clemmons DR, Klibanski A, et al. Expert consensus document: A consensus on the medical treatment of acromegaly. Nat Rev Endocrinol. 2014;10:243-8.

[6] Larsson S, Lawyer P, Garellick G, Lindahl B, Lundstrom M. Use of 13 disease registries in 5 countries demonstrates the potential to use outcome data to improve health care's value. Health Aff (Millwood). 2012;31:220-7.

[7] Holdaway IM, Rajasoorya RC, Gamble GD. Factors influencing mortality in acromegaly. J Clin Endocrinol Metab. 2004;89:667-74.

[8] Mestron A, Webb SM, Astorga R, Benito P, Catala M, Gaztambide S, et al. Epidemiology, clinical characteristics, outcome, morbidity and mortality in acromegaly based on the Spanish Acromegaly Registry (Registro Espanol de Acromegalia, REA). Eur J Endocrinol. 2004;151:439-46. 
[9] Kauppinen-Makelin R, Sane T, Reunanen A, Valimaki MJ, Niskanen L, Markkanen H, et al. A nationwide survey of mortality in acromegaly. J Clin Endocrinol Metab. 2005;90:40816.

[10] Bex M, Abs R, T'Sjoen G, Mockel J, Velkeniers B, Muermans K, et al. AcroBel the Belgian registry on acromegaly: a survey of the 'real-life' outcome in 418 acromegalic subjects. Eur J Endocrinol. 2007;157:399-409.

[11] Anagnostis P, Efstathiadou ZA, Polyzos SA, Adamidou F, Slavakis A, Sapranidis M, et al. Acromegaly: presentation, morbidity and treatment outcomes at a single centre. Int J Clin Pract. 2011;65:896-902.

[12] Arosio M, Reimondo G, Malchiodi E, Berchialla P, Borraccino A, De Marinis L, et al. Predictors of morbidity and mortality in acromegaly: an Italian survey. Eur J Endocrinol. 2012;167:189-98.

[13] Mercieca C, Gruppetta M, Vassallo J. Epidemiology, treatment trends and outcomes of acromegaly. Eur J Intern Med. 2012;23:e206-7.

[14] Sesmilo G, Gaztambide S, Venegas E, Pico A, Del Pozo C, Blanco C, et al. Changes in acromegaly treatment over four decades in Spain: analysis of the Spanish Acromegaly Registry (REA). Pituitary. 2013;16:115-21.

[15] Vallette S, Ezzat S, Chik C, Ur E, Imran SA, Van Uum S, et al. Emerging trends in the diagnosis and treatment of acromegaly in Canada. Clin Endocrinol (Oxf). 2013;79:79-85. [16] Howlett TA, Willis D, Walker G, Wass JA, Trainer PJ, Group UKARS. Control of growth hormone and IGF1 in patients with acromegaly in the UK: responses to medical treatment with somatostatin analogues and dopamine agonists. Clin Endocrinol (Oxf). 2013;79:689-99. 
[17] Kwon O, Song YD, Kim SY, Lee EJ, Rare Disease Study Group S, Research Committee

KES. Nationwide survey of acromegaly in South Korea. Clin Endocrinol (Oxf). 2013;78:57785.

[18] Schofl C, Franz H, Grussendorf M, Honegger J, Jaursch-Hancke C, Mayr B, et al. Longterm outcome in patients with acromegaly: analysis of 1344 patients from the German Acromegaly Register. Eur J Endocrinol. 2013;168:39-47.

[19] Salvatori R, Woodmansee WW, Molitch M, Gordon MB, Lomax KG. Lanreotide extended-release aqueous-gel formulation, injected by patient, partner or healthcare provider in patients with acromegaly in the United States: 1-year data from the SODA registry. Pituitary. 2014;17:13-21.

[20] Vandeva S, Elenkova A, Natchev E, Kirilov G, Tcharaktchiev D, Yaneva M, et al. Treatment outcome results from the Bulgarian Acromegaly Database: adjuvant dopamine agonist therapy is efficient in less than one fifth of non-irradiated patients. Exp Clin Endocrinol Diabetes. 2015;123:66-71.

[21] Dal J, Feldt-Rasmussen U, Andersen M, Kristensen LO, Laurberg P, Pedersen L, et al. Acromegaly incidence, prevalence, complications and long-term prognosis: a nationwide cohort study. Eur J Endocrinol. 2016;175:181-90.

[22] Portocarrero-Ortiz LA, Vergara-Lopez A, Vidrio-Velazquez M, Uribe-Diaz AM, GarciaDominguez A, Reza-Albarran AA, et al. The Mexican Acromegaly Registry: Clinical and Biochemical Characteristics at Diagnosis and Therapeutic Outcomes. J Clin Endocrinol Metab. 2016;101:3997-4004.

[23] Vila G, Dobnig H, Knosp E, Schnack C, Franz H, Finkenstedt G, et al. Gender aspects in the biochemical control of acromegaly in Austria: evaluation of 607 cases from the Austrian Acromegaly Registry. 18th European Congress of Endocrinology. Munich, GE: Endocrine Abstract; 2016. 
[24] Khamseh ME, Mohajeri Tehrani MR, Mousavi Z, Malek M, Imani M, Hoshangian Tehrani N, et al. Iran Pituitary Tumor Registry: Description of the Program and Initial Results. Arch Iran Med. 2017;20:746-51.

[25] Maione L, Brue T, Beckers A, Delemer B, Petrossians P, Borson-Chazot F, et al. Changes in the management and comorbidities of acromegaly over three decades: the French Acromegaly Registry. Eur J Endocrinol. 2017;176:645-55.

[26] Esposito D, Ragnarsson O, Granfeldt D, Marlow T, Johannsson G, Olsson DS. Decreasing mortality and changes in treatment patterns in patients with acromegaly from a nationwide study. Eur J Endocrinol. 2018;178:459-69.

[27] Daly AF, Rixhon M, Adam C, Dempegioti A, Tichomirowa MA, Beckers A. High prevalence of pituitary adenomas: a cross-sectional study in the province of Liege, Belgium. J Clin Endocrinol Metab. 2006;91:4769-75.

[28] Fernandez A, Karavitaki N, Wass JA. Prevalence of pituitary adenomas: a communitybased, cross-sectional study in Banbury (Oxfordshire, UK). Clin Endocrinol (Oxf). $2010 ; 72: 377-82$.

[29] Petersenn S, Buchfelder M, Reincke M, Strasburger CM, Franz H, Lohmann R, et al. Results of surgical and somatostatin analog therapies and their combination in acromegaly: a retrospective analysis of the German Acromegaly Register. Eur J Endocrinol. 2008;159:52532.

[30] Jane JA, Jr., Starke RM, Elzoghby MA, Reames DL, Payne SC, Thorner MO, et al. Endoscopic transsphenoidal surgery for acromegaly: remission using modern criteria, complications, and predictors of outcome. J Clin Endocrinol Metab. 2011;96:2732-40. [31] Babu H, Ortega A, Nuno M, Dehghan A, Schweitzer A, Bonert HV, et al. Long-Term Endocrine Outcomes Following Endoscopic Endonasal Transsphenoidal Surgery for Acromegaly and Associated Prognostic Factors. Neurosurgery. 2017. 
[32] Mercado M, Gonzalez B, Vargas G, Ramirez C, de los Monteros AL, Sosa E, et al. Successful mortality reduction and control of comorbidities in patients with acromegaly followed at a highly specialized multidisciplinary clinic. J Clin Endocrinol Metab. 2014;99:4438-46.

[33] Ritvonen E, Loyttyniemi E, Jaatinen P, Ebeling T, Moilanen L, Nuutila P, et al. Mortality in acromegaly: a 20-year follow-up study. Endocr Relat Cancer. 2015;23:469-80.

[34] Bolfi F, Neves AF, Boguszewski CL, Nunes-Nogueira VS. Mortality in acromegaly decreased in the last decade: a systematic review and meta-analysis. Eur J Endocrinol. 2018;179:59-71.

[35] Dal J, Skou N, Nielsen EH, Jorgensen JO, Pedersen L. Acromegaly according to the Danish National Registry of Patients: how valid are ICD diagnoses and how do patterns of registration affect the accuracy of registry data? Clin Epidemiol. 2014;6:295-9.

[36] Schofl C, Petroff D, Tonjes A, Grussendorf M, Droste M, Stalla G, et al. Incidence of myocardial infarction and stroke in acromegaly patients: results from the German Acromegaly Registry. Pituitary. 2017;20:635-42.

[37] Colao A, Vandeva S, Pivonello R, Grasso LF, Nachev E, Auriemma RS, et al. Could different treatment approaches in acromegaly influence life expectancy? A comparative study between Bulgaria and Campania (Italy). Eur J Endocrinol. 2014;171:263-73.

[38] Carmichael JD, Broder MS, Cherepanov D, Chang E, Mamelak A, Said Q, et al. The association between biochemical control and cardiovascular risk factors in acromegaly. BMC Endocr Disord. 2017;17:15.

[39] Ayuk J, Clayton RN, Holder G, Sheppard MC, Stewart PM, Bates AS. Growth hormone and pituitary radiotherapy, but not serum insulin-like growth factor-I concentrations, predict excess mortality in patients with acromegaly. J Clin Endocrinol Metab. 2004;89:1613-7. 


\section{Figure 1}

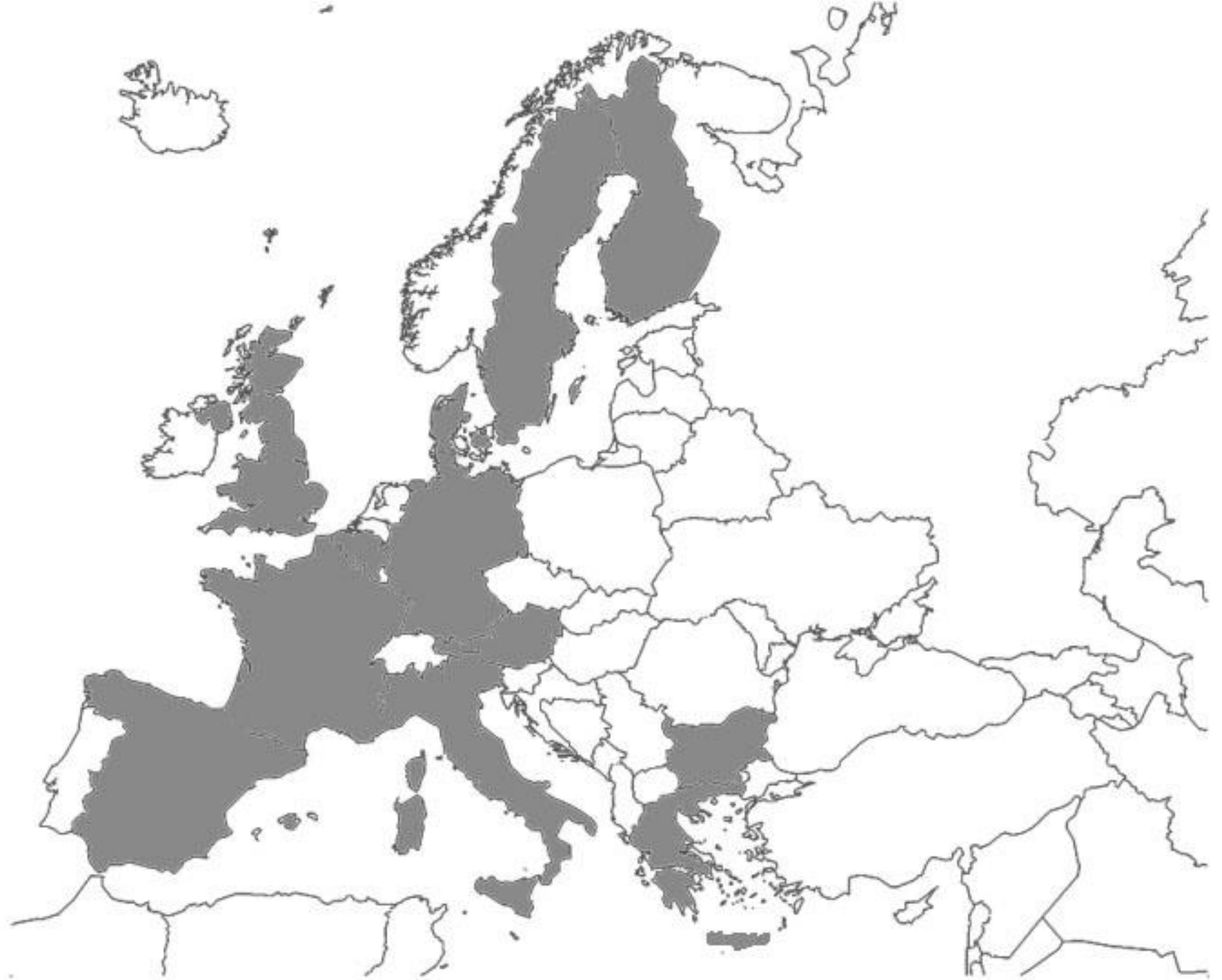




\section{Figure 2}

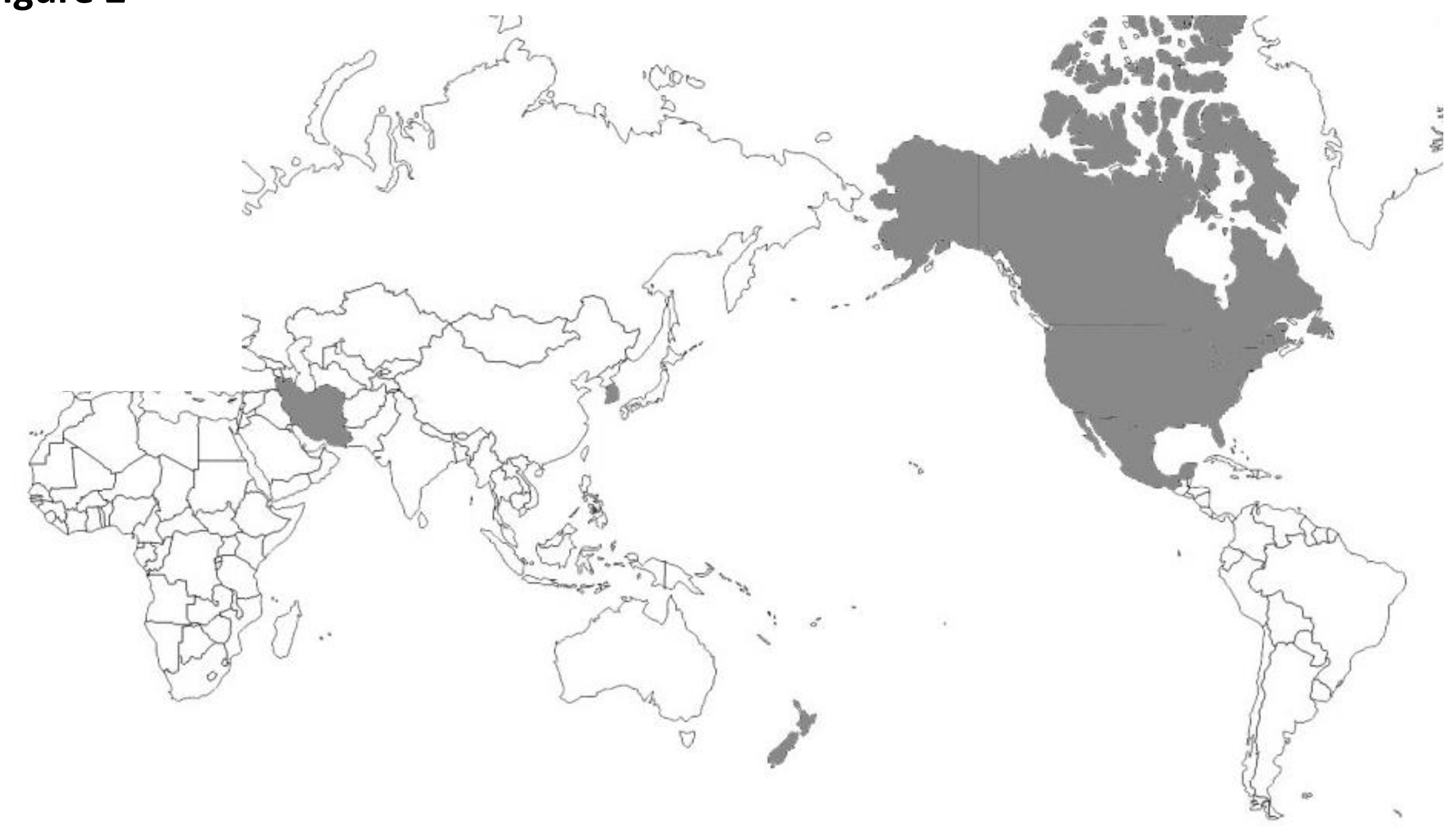


Figure 3

\section{Evolution of treatment strategy}

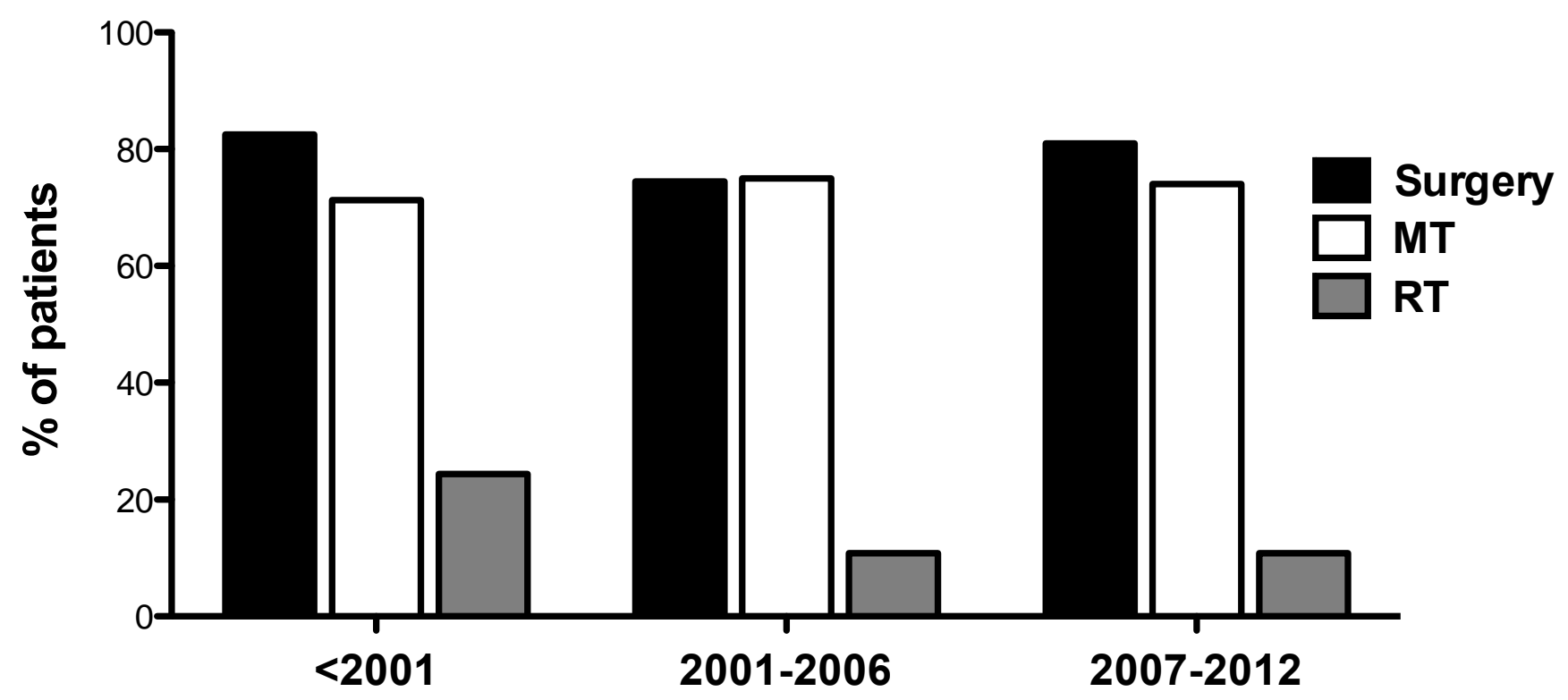


Figure 4
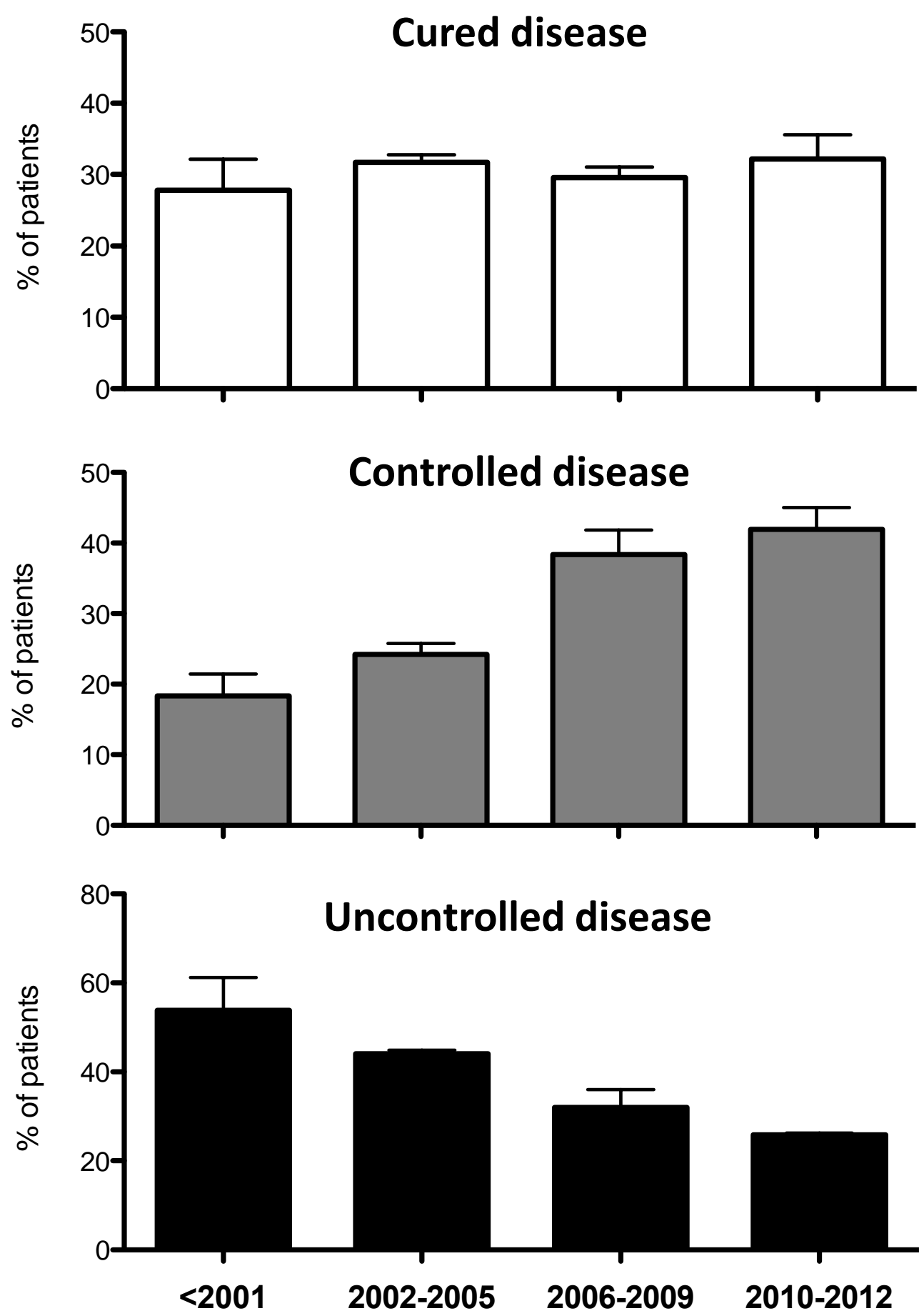


\begin{tabular}{|c|c|c|c|c|c|c|c|c|c|c|c|c|c|c|}
\hline Country & Year & No. pts & $\begin{array}{c}\text { Female to } \\
\text { male } \\
\text { ratio }\end{array}$ & $\begin{array}{c}\text { DG age } \\
\text { years }\end{array}$ & $\begin{array}{c}\mathbf{F S} \\
\text { years }\end{array}$ & $\begin{array}{c}\mathbf{F U} \\
\text { years }\end{array}$ & $\begin{array}{c}\text { MA } \\
\%\end{array}$ & $\begin{array}{c}\text { DC } \\
\%\end{array}$ & NS & MT & RT & $\begin{array}{c}\text { 1MT } \\
\%\end{array}$ & & Reference \\
\hline New Zealand & 2004 & 208 & 0.66 & 42 & 7.7 & 12.2 & 84 & 61 & 82 & 0 & 87 & 0 & & [7] \\
\hline Finland & 2005 & 334 & 1.07 & 47.5 & - & 22 & 67 & 76 & 87 & 29 & 35 & - & & [9] \\
\hline Belgium & 2007 & 418 & 0.96 & 44 & - & 11 & 79 & 56 & 68 & 78 & 34 & 23 & & [10] \\
\hline Greece & 2011 & 115 & 1.56 & 47 & - & 8.8 & 74 & 52 & 79 & 51 & 29 & 26 & & [11] \\
\hline Italy & 2012 & 1512 & 1.42 & 45 & 6.2 & 10 & 70 & 65 & 80 & 75 & 24 & - & & [12] \\
\hline Spain & 2013 & 1658 & 1.57 & 45.5 & 6 & 11 & 75 & 76 & 84 & 75 & 36 & 42 & & {$[8,14]$} \\
\hline Canada & 2013 & 649 & 0.97 & 45 & - & 10.2 & 79 & 70 & 89 & 65 & 22 & 15 & & [15] \\
\hline United States & 2013 & 166 & 2.25 & 50 & - & 7.4 & - & 72 & 80 & 74 & 20 & - & & [19] \\
\hline UK & 2013 & 2572 & 0.99 & 47.4 & - & 11 & - & 59 & 70 & 60 & 45 & 39 & & [16] \\
\hline South Korea & 2013 & 1350 & 1.15 & 44.1 & - & 4 & 83 & 46 & 90 & 46 & 9 & 4 & & [17] \\
\hline Germany & 2013 & 1344 & 1.36 & 44.5 & 5 & 8.6 & 81 & 72 & 89 & 43 & 22 & - & & {$[18,36]$} \\
\hline Bulgaria & 2014 & 534 & 1.88 & 41 & 13.7 & 7 & 70 & 51 & 86 & 49 & 30 & 7 & & [37] \\
\hline Denmark & 2016 & 405 & 0.89 & 48.7 & - & 10.6 & 69 & - & 67 & 41 & 17 & - & & [35] \\
\hline Mexico & 2016 & 2057 & 1.47 & 41.1 & - & 6 & 74 & 42 & 72 & 68 & 21 & 26 & [22] & \\
\hline Malta & 2016 & 47 & 1.14 & 43.4 & 6,3 & 14.8 & 77 & - & 72 & 70 & 53 & - & & [13] \\
\hline Austria & 2016 & 607 & 1.18 & $40-45$ & - & 11 & 80 & 71 & 89 & 44 & 22 & 11 & & [23] \\
\hline France & 2017 & 980 & 1.13 & 46 & - & 7 & 67 & 75 & 80 & 72 & 17 & 50 & & [25] \\
\hline
\end{tabular}




\begin{tabular}{|c|c|c|c|c|c|c|c|c|c|c|c|c|c|}
\hline Iran & 2017 & 85 & 0.81 & 44 & - & - & 73 & 37 & 100 & 27 & 12 & - & [24] \\
\hline Sweden & 2018 & 1089 & 1.14 & 51.6 & - & 12 & - & - & 64 & 45 & 13 & - & [26] \\
\hline Global* & - & 16,130 & 1.26 & 45.2 & 6.6 & 9.3 & 75.2 & 61.2 & 78.8 & 59.6 & 26.8 & 27.9 & \\
\hline
\end{tabular}

Table 1- Comparison of the main characteristics of disease across national registries of acromegaly. DG, diagnosis; FS, first symptoms; FU, follow up; MA, macroadenoma; DC, disease control; NS, neurosurgery; MT, medical treatment; RT, radiotherapy; 1MT, First line medical treatment. M, males; F, females. * data are expressed as weighted means except for number of patients (sum of overall patients) 


\begin{tabular}{|c|c|c|c|c|c|c|c|c|c|c|c|c|c|}
\hline Country & Year & No. pts (M) & HT & CVD & T2DM & OA & CT & OSA & CRF & HP & CP & K & Ref \\
\hline New Zealand & 2004 & $208(125)$ & 54.4 & - & 29.7 & 68.9 & - & - & - & 68 & - & - & [7] \\
\hline Belgium & 2007 & $418(213)$ & 39.4 & 5.7 & 25.3 & 46.7 & 28.1 & 17.1 & - & 39.7 & 27.2 & 10.5 & {$[10]$} \\
\hline Greece & 2011 & $115(45)$ & 46 & - & 25 & - & - & - & - & 8.4 & 55 & - & [11] \\
\hline Italy & 2012 & $1512(624)$ & 33 & - & 16.2 & - & - & - & - & - & - & - & [12] \\
\hline Spain & 2004 & $1219(478)$ & 39.1 & 7.1 & 37.6 & 19.6 & 18.7 & 13.2 & 4.9 & 25.7 & 9.5 & 7.5 & {$[8,14]$} \\
\hline Canada & 2013 & 649 (329) & 37 & - & 28 & - & - & 33 & - & 23 & - & 8.6 & [15] \\
\hline Germany & 2015 & $120(62)$ & 45 & - & 27 & - & - & 12 & - & 29.7 & - & - & $\begin{array}{l}{[18,} \\
36]\end{array}$ \\
\hline Denmark** & 2016 & $405(214)$ & 11 & - & 12 & - & - & - & 3 & - & - & - & [35] \\
\hline Mexico & 2016 & $2057(834)$ & 27 & - & 30 & - & - & - & - & - & - & - & [22] \\
\hline Malta & 2016 & $47(22)$ & 46.8 & - & 40.4 & 29.8 & 25.5 & 6.4 & - & 66 & 14.9 & 10.6 & [13] \\
\hline Austria & 2016 & $607(278)$ & 47.8 & - & 26,7 & - & - & - & - & - & - & - & [23] \\
\hline France & 2017 & $980(460)$ & 47.5 & - & 30.8 & - & - & 22.5 & - & - & 20 & - & [25] \\
\hline
\end{tabular}




\begin{tabular}{|c|c|c|c|c|c|c|c|c|c|c|c|c|c|}
\hline United States & 2017 & $121(55)$ & 32.8 & 1.2 & 21.8 & 37.7 & 29.5 & 25.6 & 2.9 & 30.8 & 27.7 & 10.0 & [38] \\
\hline Sweden & 2018 & 1089 (509) & - & - & - & - & - & - & - & 34 & - & - & [26] \\
\hline Global* & - & $9,547(4,248)$ & 35.7 & 6.4 & 27.1 & 21.4 & 21.2 & 20.1 & 4.3 & 22.2 & 18.3 & 8.5 & \\
\hline
\end{tabular}

Table 2 - Prevalence of acromegaly-related comorbidities across national or local registries of acromegaly

Pts: patients; HT : arterial hypertension; CVD: cerebro-vascular disease; T2DM: type 2 diabetes mellitus; OA: osteoarthropathy; CT: carpal tunnel; OSA: obstructive sleep apnoea; CRF: chronic respiratory failure; HP: hypopituitarism (any type); CP: colonic polyps; K: cancer.

* data are expressed as weighted means except for number of patients (sum of overall patients) 


\begin{tabular}{|c|c|c|c|c|c|c|c|}
\hline Country & Year & No. Pts & $\begin{array}{c}\text { No. } \\
\text { deaths }\end{array}$ & MAD & SMR & CI $95 \%$ & Reference \\
\hline New Zealand & 2004 & 208 & 72 & 61 & 2.70 & $2.10-3.50$ & [7] \\
\hline UK & 2004 & 419 & 95 & 53 & 1.26 & $1.03-1.54$ & [39] \\
\hline Spain & 2004 & 1219 & 56 & - & - & - & {$[8]$} \\
\hline Finland* & 2005 & 334 & 56 & 68 & 1.16 & $0.85-1.54$ & [9] \\
\hline Belgium & 2007 & 418 & 28 & 71 & 1.39 & $0.96-2.03$ & {$[10]$} \\
\hline Italy & 2012 & 1512 & 61 & 66.5 & 1.13 & $0.87-1.46$ & {$[12]$} \\
\hline Canada & 2013 & 649 & 26 & 58 & - & - & [15] \\
\hline Mexico & 2014 & 442 & 22 & 58.6 & 0.72 & $0.41-1.03$ & {$[32]$} \\
\hline Denmark & 2016 & 405 & 73 & - & 1.3 & $1.0-1.7$ & [35] \\
\hline Finland* & 2016 & 333 & 113 & 74 & 1.90 & $1.53-2.34$ & [33] \\
\hline Austria & 2016 & 607 & 19 & 68.8 & - & - & [23] \\
\hline France & 2017 & 980 & 41 & 62.8 & 1.05 & $0.70-1.42$ & [25] \\
\hline Iran & 2017 & 85 & 1 & - & - & - & [24] \\
\hline Sweden & 2018 & 1089 & 232 & - & 2.79 & $2.43-3.15$ & [26] \\
\hline
\end{tabular}

Table 3 - Mortality data across national or local registries of acromegaly. Pts: patients; MAD: median age at death; SMR: standardized mortality ratio; CI: confidence interval; *Please note that Finnish cohort has been published twice (2005 and 2016). The latter includes former patients with a longer follow-up. 